Please cite the official published version of this article:

'Absolute Biological Needs', Bioethics 28 (2014): 293-301.

http://dx.doi.org/10.1111/bioe.12020

\title{
ABSOLUTE BIOLOGICAL NEEDS
}

\section{STEPHEN McLEOD}

skmcleod@liv.ac.uk

\begin{abstract}
Absolute needs (as against instrumental needs) are independent of the ends, goals and purposes of personal agents. Against the view that the only needs are instrumental needs, David Wiggins and Garrett Thomson have defended absolute needs on the grounds that the verb 'need' has instrumental and absolute senses. While remaining neutral about it, this article does not adopt that approach. Instead, it suggests that there are absolute biological needs. The absolute nature of these needs is defended by appeal to: their objectivity (as against mind-dependence); the universality of the phenomenon of needing across the plant and animal kingdoms; the impossibility that biological needs depend wholly upon the exercise of the abilities characteristic of personal agency; the contention that the possession of biological needs is prior to the possession of the abilities characteristic of personal agency. Finally, three philosophical usages of 'normative' are distinguished. On two of these, to describe a phenomenon or claim as 'normative' is to describe it as value-dependent. A description of a phenomenon or claim as 'normative' in the third sense does not entail such value-dependency, though it leaves open the possibility that value depends upon the
\end{abstract}


phenomenon or upon the truth of the claim. It is argued that while survival needs (or claims about them) may well be normative in this third sense, they are normative in neither of the first two. Thus, the idea of absolute need is not inherently normative in either of the first two senses.

\section{Keywords}

absolute needs, biological needs, instrumental needs, needs, normativity, personal agents, value

\section{INSTRUMENTAL AND ABSOLUTE NEEDS}

A conceptual distinction between instrumental needs and absolute needs can be drawn, although instrumentalists about need have it that the distinction is empty on the absolute side. This section draws a conceptual distinction between instrumental and absolute need, compares and contrasts the idea of absolute needs with that of Rawlsian primary goods and suggests, independently of considerations about the semantics of the verb 'need', that there are absolute needs. The article proceeds to offer some arguments, in the four sections that follow, for the view that there are absolute biological needs. The arguments offered for the absoluteness of these biological needs appeal, respectively, to their objectivity, their universality across species in the plant and animal kingdoms, to their independence from the exercise of the abilities characteristic of personal agency and to their independence from the possession of those abilities. Finally, three philosophical usages of 'normative' are distinguished. On two of these, to describe a phenomenon or claim as 'normative' is to describe it as value-dependent. A description of a phenomenon or claim as 'normative' in the third sense does not entail such value-dependency, though it leaves open the possibility that 
value depends upon the phenomenon or upon the truth of the claim. It is argued that while survival needs (or claims about them) may well be normative in this third sense, they are normative in neither of the first two.

Instrumental needs are needs that are relative to ends, goals or purposes. An end, goal or purpose is not merely an outcome or situation. Rather, it is a putative outcome or situation that an agent intends to bring about or contemplates bringing about. Thus, instrumental needs exist only if there are agents which can formulate intentions and deliberate. Absolute needs are those needs (if any) that are independent of such ends, goals or purposes. Many writers on need adopt the view, called 'instrumentalism', that all needs are instrumental. Absolutism about needs, on the other hand, is the view that some needs are 'absolute', 'categorical', 'intrinsic' or 'fundamental' in the sense that they do not depend for their being upon ends, goals or purposes. Rather, the beings that have these needs do so independently of ends, goals and purposes. We may distinguish between instrumental needs that are dependent upon particular purposes or conceptions of the good (e.g. the need to practice in order to cultivate excellence in musical performance) and instrumental needs the satisfaction of which contributes to the furtherance of whatever purposes or conception of the good an agent may have, such as the need for the 'primary goods' recognized by Rawls, where each primary good is a means towards the realization of any thick conception of the good:

though men's rational plans [...] have different final ends, they nevertheless all require for their execution certain primary goods, natural and social. [. . .] whatever one's system of ends, primary goods are necessary means. ${ }^{1}$

\footnotetext{
${ }^{1}$ J. Rawls. 1972. A Theory of Justice. Cambridge, MA: Harvard University Press: 93.
} 
Primary goods are instruments towards attaining one's ends whatever one's ends may be. Rawls adds that 'the persons in the original position [.. .] know [...] that they prefer more rather than less primary goods'. This suggests that the more primary goods a person has the better able that person will be to pursue their ends: one can never have too much of a primary good. Indeed, when Rawls gives examples of primary goods, they are all of goods that are supposedly perfectible (i.e. of which it is supposed that one can never have too much):

rights and liberties, powers and opportunities, income and wealth [...] are [. . ] social primary goods. Other primary goods such as health and vigor, intelligence and imagination, are natural goods; although their possession is influenced by the basic structure [of society], they are not so directly under its control. ${ }^{2}$

Supposing that some needs really are absolute, having one's absolute needs met is not a primary good akin to these examples, since one's absolute needs set limits to their satisfaction: one needs to eat, but one also needs not to overeat. ${ }^{3}$ Nevertheless, having access to an adequate supply of food is a primary good in the sense that it is necessary whatever one's 'system of ends'. When the satisfaction of an absolute need is a primary good in that sense, this is a functional role that the satisfaction of the need plays as the need of a person with a system of ends. The idea of an absolute need itself, however, is of a need that is ontologically independent of all purposes and conceptions of the good. For there to be organisms with absolute needs it is not necessary that there be organisms that are able to formulate intentions or systems of ends.

\footnotetext{
${ }^{2}$ Ibid: 62 .

${ }^{3}$ The point that needs set limits to the means of meeting them was made to me in the 1990 s by Scott Meikle.
} 
Our needs have satisfiers. Supposing that there are absolute needs, an entity can at the same time satisfy both an instrumental and an absolute need. For example, a person's house can both satisfy their absolute need for shelter and provide the opportunity for that person to attain a long-held ambition of starting a family. The need for shelter (unlike the need for an environment in which to implement a project that is a matter of desire alone) requires satisfaction if one is not to suffer harm. Although one can forsake its satisfaction, one cannot forsake the need for shelter. ${ }^{4}$ Though the needs in this example are satisfied by the same entity, they remain distinct needs. While one thing may satisfy both an instrumental and an absolute need, this does not compromise the conceptual distinction between instrumental and absolute needs.

Claims of need often omit any mention of ends, purposes or goals and simply have the form 'A needs $\mathrm{X}$ ' or 'A needs to $\mathrm{V}$ '. Let 'A needs to $\mathrm{X} /$ to $\mathrm{V}$ ' stand for any claim with one of these forms. It is debated as to whether claims of the form ' $\mathrm{A}$ needs $\mathrm{X} /$ to $\mathrm{V}$ ' are always elliptical for claims of the form 'A needs $\mathrm{X} /$ to $\mathrm{V}$ in order to $\mathrm{F}$ ', where ' $\mathrm{F}$ ' stands for that for which $\mathrm{X}$, or V-ing, is needed. Instrumentalists about need hold that such claims are always elliptical in that way and, further, (though they do not appear always to recognize that it is a further claim) that that for which $\mathrm{X}$, or V-ing is needed is always an end, purpose or goal. ${ }^{5}$

One way of arguing against instrumentalism maintains that some claims of the form 'A needs $\mathrm{X} /$ to $\mathrm{V}$ ' are not elliptical. Wiggins holds that sentences of the form 'A needs X' exhibit two senses of 'need'. In the first, instrumental sense, 'need' points to an unspecified purpose. In the second, absolute sense, 'need' already 'fixes' the purpose:

\footnotetext{
${ }^{4}$ On the unforsakable nature of non-instrumental needs, see further G. Thomson. 1987. Needs. London: Routledge \& Kegan Paul, especially Chapter 2.

${ }^{5}$ See A. Flew. 1981. The Politics of Procrustes. New York: Prometheus: 120-123; H.G. Frankfurt. Necessity and Desire. Philos Phenomenol Res 1984; 45: 1-13: esp. 2-3.
} 
although there is an instrumental sense of 'need' where we can ask for some purpose to be specified in a non-elliptical version of the 'needs' claim and there are no limits on what this purpose is (except the limits of what can be of any conceivable concern to anyone), there is another sense of 'need' by which the purpose is already fixed, and fixed in virtue of the meaning of the word. ${ }^{6}$

When someone claims that they need something for a certain end, a possible reply is that (in one sense) they do not in fact need what they claim to need because they do not need to have the end. In Wiggins’s example, if a man claims to need $£ 200$ to buy a suit we may acknowledge this but insist that he does not need $£ 200$ because he does not need to buy the suit. If all need claims were, as instrumentalists suggest, elliptical, then the man ought to be able to refute us just by specifying an end for which he needs the suit. This, thinks Wiggins, would constitute 'deliberate misunderstanding' of what we were saying. ${ }^{7}$ Wiggins concludes that 'What [the man] has to show, if he wants to make more than the instrumental claim, is that he cannot get on without that suit, that his life will be blighted without it, or some such thing, 8

To say that in non-elliptical need claims the purpose is fixed is not to contest the view that needing is essentially purposive. Wiggins's remark gives the impression that all need claims involve purposes, sometimes 'fixed' by the usage of the verb 'need' that is involved and sometimes not so 'fixed'. In order to reject instrumentalism, construed as a claim about

\footnotetext{
${ }^{6}$ D. Wiggins. 1991. Claims of Need. In Needs, Values, Truth, 2nd edn, Oxford: Blackwell: 1-57: 9. (Originally published in 1985, in Morality and Objectivity, T. Honderich, ed. London: Routledge \& Kegan Paul: 149-202.)

${ }^{7}$ Ibid: 8 .

${ }^{8}$ Ibid: $8-9$.
} 
the nature of needing, it is inadequate (and it does not seem to have been Wiggins' intention) to accept the claim that all needing is purposive but to reject the ellipse theory. By the lights of the conceptual distinction between absolute and instrumental need with which this article is working, absolute need is not a special kind of instrumental need: it is wholly distinct in kind from instrumental need.

According to Wiggins, the following equivalences hold:

I need [absolutely] to have $x$ if and only if

I need [instrumentally] to have $x$ if I am to avoid being harmed if and only if

It is necessary, things being what they actually are, that if I avoid being harmed then I have $x .^{9}$

This again presents the danger that absolute need will be construed as a special kind of instrumental need. Presuming that the equivalences in the quotation from Wiggins hold, they do not generalize to cases that are not first-person cases. 'A needs [absolutely] to have $x$ ' is not equivalent to 'A needs [instrumentally] to have $x$ if $\mathrm{A}$ is to avoid being harmed', since $\mathrm{A}$ may not be the kind of organism that can conceive of and pursue any ends and so not be the kind of entity that can need anything instrumentally. Moreover, A may not be an organism that anyone wants to survive or to flourish. In that circumstance, A will not have any 'proxy' instrumental needs (i.e. needs relative to the ends of another being).

\footnotetext{
${ }^{9}$ Ibid: 10 . The square brackets and the words therein are included in the original source.
} 
What one needs instrumentally is determined by one's intentions, as well as by how the world is apart from these intentions. Intentions are irrelevant to absolute needing. ${ }^{10}$ So, absolute need is not a special kind of instrumental need. Thomson remarks that:

The schema

$\mathrm{X}$ is a necessary condition of A's f-ing in circumstances

$\mathrm{C}$

depicts the logical shape of all [need] statements. [. . .] This means that all 'need' categories should be explained in terms of the logical constraints they place on the antecedent 'A's f-ing' in the schema. For instance, the concept of an instrumental need places the restriction on antecedent 'A's f-ing' that it must be some aim or goal of A's. The concept of a fundamental need determines that 'A's f-ing' must stand for 'A's not suffering serious harm'. Explained in this way the various categories of 'need' usage have a unity. ${ }^{11}$

Thomson's comments do not (and were not intended to) entail that f-ing is always a purpose, aim or goal, as opposed merely to an outcome. By a 'fundamental' need Thomson means a need that is non-instrumental.

Wiggins writes, on the one hand, that absolute needing is 'more than merely instrumental' (i.e. instrumental plus something), and, on the other, that it is 'non-

\footnotetext{
${ }^{10}$ Compare, e.g. ibid: 6 .

11 Thomson, op. cit. note 4, p. 10.
} 
instrumental' (i.e. not a kind of instrumental needing). ${ }^{12}$ The latter remark is the one that supports the conception of absolute need with which this article is concerned. As we have seen, if some needs really are absolute, what one needs absolutely one can also need instrumentally. In this circumstance, the entity needed is needed 'more than merely' instrumentally. Nevertheless, being needed absolutely is not being needed instrumentally plus something. When materials, commodities or goods needed absolutely are also needed instrumentally, they would still be needed absolutely even if they were not needed instrumentally.

In conclusion, a strong conceptual distinction can be drawn between absolute and instrumental need, independently of the contention that the verb 'need' has two senses. In the next four sections, arguments are offered for the view that the distinction between absolute and instrumental needs is not empty on the absolute side, since there are absolute biological needs.

\section{OBJECTIVE BIOLOGICAL NEEDS}

If all needs were instrumental then all needs would be ontologically dependent upon (and so would not exist but for) psychological factors such as aims, intentions and desires. There are biological needs, such as the need for nutrition, which are objective in the sense that they are ontologically independent of psychological factors: the biological needs in question could have existed even if there had been no conscious organisms.

Let us consider a classification which does not leave room for biological needs that are objective in the sense that they are ontologically independent of psychological factors, so as to bring to light that this is a deficiency in that classification. Taylor distinguishes between those "“need" statements' which are 'purely normative' and those which are (wholly or

\footnotetext{
${ }^{12}$ Wiggins, op. cit. note 6, p. 13.
} 
partly) factual. ${ }^{13}$ Among the factual need claims, Taylor includes: (1) statements of what 'is required or demanded by a prescriptive rule or law'; (2) statements 'in which the somethingthat-is needed is a necessary means to the attainment of a goal of the person who is said to have the need'; ${ }^{14}$ (3) statements about the 'dominant conative dispositions of typical members of $[\ldots]$ groups or societies'. ${ }^{15}$

Presuming that statements of biological need are factual, they do not fall under type (1). Since not all organisms are persons, but all organisms do have biological needs, statements of biological need do not fall under type (2). Finally, biological needs are not encompassed by statements of type (3). Taylor regards the needs corresponding to statements of type (3), as the word 'conative' suggests, as dependent upon psychological factors: 'a need in this sense is a comparatively strong "drive", "wish", or "motive", 16

The need for food is a form of the more abstract need for nutrition. Suppose that we construe the word 'food' as referring to stuff that an organism would eat, rather than merely ingest. Even in the unlikely event that all organisms that eat are conscious, not all organisms that need nutrients are conscious. Taylor's classification does not leave sufficient room for such biological needs as the need for nutrition, since it views all needs that are not dependent

\footnotetext{
${ }^{13}$ P.W. Taylor. 'Need' Statements. Analysis 1959; 19: 106-111: 110.

${ }^{14}$ Ibid: 107.

${ }^{15}$ Ibid: 109 .

${ }^{16}$ Ibid: 108. Taylor writes that the "biological" or "physiological" dispositions of hunger, rest, and sex, and such things as food, sleep, and a sexual mate, would be instances of human needs not peculiar to man' (ibid: 109). Food satisfies the need for food. Hunger is indicative of, but distinct from, that same need. If hunger is a need, then - in contrast with the need for food - it is its own satisfier. When hunger occurs it is normally nutrition that is needed. It is not the episode of hunger that is needed. A man who needs to eat but is not hungry will not suffer harm so long as he does eat. Absolute needs, however, are such they their non-satisfaction over a prolonged period will result in harm to the organism.
} 
on pure prescription as either dependent upon a person's goals or as dependent upon motivational factors: in other words, all such needs are taken by Taylor to be psychologically-dependent.

The need for nutrition is objective in the sense that it does not depend for its existence upon matters psychological. ${ }^{17}$ It is an example of a biological need that cannot be essentially instrumental.

\section{THE UNIVERSALITY OF BIOLOGICAL NEED}

We may distinguish between: existence needs, the satisfaction of which is necessary for an organism's survival; welfare needs, the satisfaction of which is necessary for the prevention of harm to the organism; and perfectionist needs, the satisfaction of which is necessary if the organism is to flourish. ${ }^{18}$

In the plant and animal kingdoms, biological need is universal in the sense that each and every organism has biological needs. Unlike absolute needs, ends, purposes and goals are desire-dependent. Not all organisms have desires, but all organisms have biological needs. ${ }^{19}$

\footnotetext{
${ }^{17}$ Compare R. Geuss. Economies: Good, Bad, Indifferent. Inquiry: An Interdisciplinary Journal of Philosophy 2012; 55: 331-360: 333 where it is entertained that the human need for water is 'pre-verbal, non-subjective [...] and $[\ldots]$ rooted in the nature of things, specifically in human biology, whether I or anyone knows about it or is able to formulate it in thought or language'.

${ }^{18}$ Compare S.K. McLeod. Knowledge of Need. International Journal of Philosophical Studies 2011; 19: 211230: 213. On the conception of need being employed here, no needs are prior to the organisms that have them. A human being's existence needs are not such that, if they are unsatisfied, the human being will not come into existence. Rather, if the needs are not satisfied then the human being will, as a consequence, cease to exist. Satisfaction and non-satisfaction of a need are circumstances that depend upon the existence of the needful being.

${ }^{19}$ Compare P.A. Corning. Biological Adaptation in Human Societies: A 'Basic Needs' Approach. Journal of Bioeconomics 2000; 2: 41-86: 61.
} 
So, no characterization of need can be correct that entails that all of an organism's needs depend upon ends, purposes or goals.

If all true need claims of the forms 'A needs $\mathrm{X}$ ' and 'A needs to $\mathrm{V}$ ' were only true relative to ends, then the needs of organisms that do not have ends would have to be dependent upon the ends of beings, like us, that do have ends. Now, as Anscombe once observed, the needfulness of organisms that do not have ends does not depend on the ends of other beings that do:

To say that [an organism] needs [a certain] environment is not to say, e.g., that you want it to have that environment, but that it won't flourish unless it has it. Certainly, it all depends whether you want it to flourish! [. . .] But what 'all depends' on whether you want it to flourish is whether the fact that it needs that environment, or won't flourish without it, has the slightest influence on your actions $[\ldots]^{20}$

There are true need claims about needful beings that do not have ends. Those claims are not of Taylor's type (2): i.e. they are not about instrumental means-end relationships. Some needful beings (i.e. those without ends) have absolute needs. Now human beings are organisms that are normally, at some stage in their lives, personal agents. Such agents can have consciously mediated projects not given to them by their biological natures. Human persons do not have self-sustaining natures. They cannot, by an act of will or otherwise, secure the unlimited continuance of their lives or their agency. To be a human person is to be a human being with certain capacities and social roles. These capacities and roles are shared neither by all advanced mammals nor by all members of our own species. Our biological humanity is prior to our ability to have projects and subjective interests (i.e.

\footnotetext{
${ }^{20}$ G.E.M. Anscombe. Modern Moral Philosophy. Philosophy 1958; 33: 1-19: 7.
} 
interests of which one is aware, which are 'live' interests from one's own point-of-view) not shared by all fellow members of our species. Having such projects and interests is an aspect of the normal functioning of adult humans; their absence is indicative of some form of ill health. Biological needs have to be satisfied before a human being can have the sorts of projects and subjective interests characteristic of personal agents. ${ }^{21}$

What we need to 'survive' as personal agents includes, but outstrips, what we need to survive as human organisms. The mere continuity of a human being qua organism is insufficient for continuity of personal agency. Our welfare and perfectionist needs are not independent of psychological factors, since a flourishing human adult will be a personal agent and the welfare and flourishing of personal agents include (but are not wholly constituted by) psychological satisfactions. Statements of need are on a spectrum that goes from the purely factual to the heavily evaluative: statements of survival need are at the factual extremity of the spectrum; statements of perfectionist agency needs are at the evaluative extremity. ${ }^{22}$ What we need if we are to flourish as agents includes, but far outstrips, what we need if we are to survive. Unlike the notion of flourishing, the notion of survival is evidently not value-laden. It is not an evaluative matter but an empirical matter as to what an organism needs for survival. $^{23}$

One is unable to survive unharmed if one is, for a prolonged period, without that which one absolutely needs. This of course entails that if one wants to survive unharmed then one instrumentally needs what one absolutely needs. However, one's needing what one

\footnotetext{
${ }^{21}$ Compare S.C. Miller. 2012. The Ethics of Need. New York: Routledge: 24-25; A.A.A. Alvarez. The CrossCultural Importance of Satisfying Vital Needs. Bioethics 2009; 23: 486-496, e.g. 487.

${ }^{22}$ Compare Corning, op. cit. note 19, pp. 66-67.

${ }^{23}$ Compare McLeod, op. cit. note 18.
} 
absolutely needs is not dependent upon one's wanting to avoid harm or death. It is the hunger-striker's knowledge that he needs food (not his knowledge that if he wanted, above all, to live healthily, then he would need food) that informs his decision to go on hunger strike. To make a need claim, such as the claim that all humans need food, need not involve making a moral demand or prescribing that the need be met. The hunger striker may agree that all humans need food, but insist that he wants none. One can recognize one's absolute need while renouncing its satisfaction. ${ }^{24}$

In virtue of their biological humanity, human persons have biological needs which are independent of their status as personal agents, many of which are common to all terrestrial mammals and some of which are common to all organisms. The biological needs of human beings 'routinely impose themselves on the daily rhythms of our lives' ${ }^{25}$ In that sense, such needs are 'external' to our personal projects and goals. If we are so busy with our personal projects and goals that we neglect to satisfy some of our biological welfare needs, we suffer discomfort, pain or other forms of distress or harm. One's goals or projects may involve, as in the case of the hunger-striker, self-inflicted harm that is knowingly brought about. The hunger striker does not instrumentally need to eat, but his knowledge that he noninstrumentally needs to eat (i.e. that he will suffer harm, no matter what his other desires, if he does not eat and no-one intervenes without his consent) is part of what makes his form of protest an intelligible piece of behaviour. There are occasions on which recognition of one's absolute need is what underlies the intelligibility of renouncing its satisfaction and 'trumping' it with an instrumental need to which the absolute need is contrary. We can knowingly want that which we know to conflict with what we absolutely need.

\footnotetext{
${ }^{24}$ Compare Guess, op. cit. note 17 , p. 341.

${ }^{25}$ Corning, op. cit. note 19 , p. 47.
} 
All organisms have biological needs that are not chosen. Non-conscious organisms have biological needs that are not conferred upon them by conscious organisms. Non-human conscious organisms have biological needs that are not conferred upon them by human beings. Human beings have biological needs that they do not confer upon themselves and which have not been conferred upon them by other human beings. The next section and the one that follows argue for the related points that, although a person's actions may result in the person's having certain of the absolute needs that the person has, it is not as a result of anyone's action that the person has absolute biological needs. Rather, a personal agent has biological needs that are prior both to the exercise of the abilities characteristic of personal agency and to the possession of those abilities. ${ }^{26}$

\section{EXERCISE-INDEPENDENT BIOLOGICAL NEEDS}

When a personal agent has an unmet need, this can present the risk that the range or efficacy of the agent's abilities will be diminished. If an adult human being is to have the range of abilities characteristic of normal functioning in a human adult, that adult's biological welfare needs must be satisfied. ${ }^{27}$ Human beings have survival needs, the satisfaction of which is necessary to the continuance of their lives, and welfare needs, the satisfaction of which is necessary to the avoidance of harm. A human adult whose biological welfare needs go unsatisfied for a prolonged period but who survives will go into decline and suffer a narrowing or diminution of his or her effective agency. A child whose biological welfare

\footnotetext{
${ }^{26}$ Compare G. Thomson. Deseos y Necesidades. Ideas y Valores 1998; 107: 43-55: 53; Thomson, op. cit. note 4, Chapter 2.

${ }^{27}$ Compare Miller, op. cit. note 21, pp. 11-12: 'Before one can express a preference, one must be able to function as an agent $[\ldots]$ it is through need meeting that agency is established.' Compare also Alvarez, op. cit. note 21 , passim.
} 
needs go unsatisfied over a prolonged period will not develop into a normally functioning adult. $^{28}$

Given that the satisfaction of some biological needs is prior to the possession of the abilities characteristic of personal agency, it cannot be the case that all needs depend upon the exercise of those abilities. ${ }^{29}$ So long as the distinction between abilities and their exercise is maintained, a philosophy of need which says that all needs are instrumental entails that all needs depend upon the exercise of those abilities. Such a philosophy contends that every need depends upon an end. When one has an end, one has exercised one's ability to formulate ends; often, one has exercised one's ability to deliberate. Some of the needs that an organism has are exercise-independent in the sense that they do not depend upon how (or even whether) the organism has exercised its abilities. This is not, of course, to deny that the exercise of an ability can bring about a need. The point is just that not all needs can be like that. For example, my need to breathe does not arise from my ability to breathe and nor does it arise from its exercise. ${ }^{30}$ Indeed, it arises neither from any ability of mine nor from the exercise of any ability of mine.

The real distinction between needs that arise from the exercise of an ability of the needful organism and those that are independent of the exercise of any such ability supports (but is not the same as) the real distinction the absolutist makes between instrumental and absolute needs. If I do something risky and as a result suffer harm, then this may bring about particular absolute needs that have arisen from the exercise of my ability to participate in the

\footnotetext{
${ }^{28}$ Compare Corning, op. cit. note 19, p. 61; Geuss, op. cit. note 17, pp. 334-335.

${ }^{29}$ Compare Alvarez, op. cit. note 21, e.g. p. 488.

30 'A needs to $\mathrm{V}$ ' does not entail ' $\mathrm{A}$ is able to $\mathrm{V}$ '. The relationship between need and ability is therefore not akin to the relationship usually taken to obtain between alethic necessity and possibility (whereby, if it is necessary that $P$ then it is possible that $P$ ). Indeed, it may be precisely my need to $\mathrm{V}$ but my inability to do so, or the wider impossibility of doing so, that brings about my demise.
} 
risky activity. For example, I may go skiing, have an accident, break some bones and need medical treatment. So, there is reason for thinking that not all absolute needs are exerciseindependent. Even if not all absolute needs are exercise-independent needs, however, there are exercise-independent needs and all such needs are absolute. Given the distinction between abilities and their exercise, the instrumentalist's position requires the instrumentalist to deny that there is exercise-independent needing. A philosophical motive for such a denial, other than some insistence that there is no modality (and so no needfulness) in nature, seems elusive. In any case, insisting that there is no modality in nature is not an option for the instrumentalist, since the instrumentalist does not hold that the 'must' that is included or entailed by the consequent in a needs claim reformulated as a hypothetical imperative expresses a modality that is to be accounted for by subjectivist or expressivist means. For example, take the reformulation of 'you need this medicine' as 'if you want to survive, then you must take this medicine'. If the 'must' were a subjective one, then one could change one's needs not only by changing one's desires, but by changing one's modal opinions (i.e. one's opinions as to what is possible). If the 'must' were to be accounted for by expressivist means, then the instrumentalist's commitment to the literal (albeit end-relative) truth of claims of need would have to be forsaken, presuming that a true conditional cannot contain a pseudo-statement as its consequent. The instrumentalist might attempt to escape this, in turn, by rejecting the view that need claims are modal at all, but that response would be inconsistent with the linguistic data. Minimally, we can conclude that if need claims are modal then the thesis that the only true need claims are true relative to ends is false. The only way out for the instrumentalist, it seems, would be a demonstration of the semantic eliminability of the verb 'to need' in favour of some non-modal analysis of need claims. The argument from the existence of need that is not dependent on the prior exercise of any of the needful being in question's abilities puts the burden of proof on the instrumentalist. 


\section{AGENCY-INDEPENDENT BIOLOGICAL NEEDS}

It is a short step from the exercise-independence of some needs to their agency-independence. Instrumental need is, given the nature of its exercise-dependency, always a product of agency. Need, however, is not always the product of agency. The ability to have instrumental needs is dependent upon the satisfaction of absolute needs. ${ }^{31}$ Even the most self-sufficient people are needful, dependent beings; indeed, those who advocate ways of life that put an emphasis on self-sufficiency tend to emphasize, rather than deny, human dependency. Human neonates have needs, but those needs are not the products of the neonates' own agency as they are too young to be agents. A human neonate is a pure patient (i.e. a patient that is not a personal agent). ${ }^{32}$ Consider Tom, one such neonate. Tom's existence is a product of human agency, in that it has been caused by an act of sexual intercourse. That there is this being, Tom, with these absolute needs, is a product of agency. Nonetheless, it is not a product of agency that Tom has absolute needs. We can compare the case with this. It is not an agentindependent matter that there is such a human being as Tom. It is an agent-independent matter that Tom is human.

Human beings become (and can cease to be) personal agents. Personal agent is a phased sortal (i.e. a sortal concept that can apply to a substance that falls under it for only part of that substance's 'life-history'). A human being is a patient before it is a personal agent.

\footnotetext{
${ }^{31}$ Compare Alvarez, op. cit. note 21, e.g. p. 490.

${ }^{32}$ The relevance of the notion of being a patient to the discussion of need and its place in ethics is emphasized in S. Reader. 2007. Needs and Moral Necessity. London: Routledge, passim. Human beings who are personal agents are also patients. Moral philosophers, especially in the Kantian tradition, tend to emphasize the notion of agency and neglect that of patiency. On the role of the idea of patiency in Kant's own moral thought, see Miller, op. cit. note 21 , e.g. pp. 53-60.
} 
The priority of a human being's humanity to their personal agency is not only temporal but developmental and (arguably) ontological. The satisfaction of a child's biological needs is developmentally prior to its having non-biological agency needs (i.e. needs the satisfaction of which is necessary for the continuance, maintenance or enhancement of personal agency rather than mere biological humanity). The satisfaction of agency needs, in turn, is prior to the having of instrumental needs of one's own, since having instrumental needs of one's own is a product of the exercise of those abilities that constitute one's personal agency.

A need is not a substance, but a condition of dependency (whether satisfied or not). ${ }^{33}$ A needful situation may be an unavoidable aspect of the needful organism's life as a member of the species to which it belongs, or it may arise from circumstances not shared by other members of the species. Accordingly, we may distinguish, for example, between universal biological welfare needs, which are common to all members of a species, and particular biological welfare needs, which vary, within the species, from individual to individual. An environmental or genetic factor may result in an organism having a particular absolute need that is not common to all members of its species. For example, all human beings need food but individuals differ in their specific nutritional requirements. ${ }^{34}$ People with some conditions affecting coronary health need to consume an above-average amount of food rich in omega-3 oils. Miller writes:

\footnotetext{
${ }^{33}$ Compare Wiggins, op. cit. note 6, p. 16.

${ }^{34}$ Compare P. Bloomfield. 2001. Moral Reality. New York: Oxford University Press: 37; Corning, op. cit. note 19, pp. 64-65.
} 
I understand fundamental needs to be needs that others must meet in order for a person (1) to avoid significant harm; (2) to be able to choose and carry-out action in the world; and (3) to be self-determining. ${ }^{35}$

Miller also holds, though not apparently as matter of stipulation, that fundamental needs are universal and immutable: if a need is particular or mutable, then it is not in her view fundamental. ${ }^{36}$ However, it is only at a certain level of abstraction that needs which meet her conditions (1)-(3) are universal and immutable. The human need for nutrition is universal and immutable. The need for daily access to a kidney dialysis machine is neither universal nor immutable, but it could meet all three of Miller's conditions. Miller's claim (ibid.) that what one needs 'objectively', as against what one believes one needs, 'never changes' is mistaken. The needs of the neonate are not the same as those of the adult. When one becomes ill, one may acquire needs one did not previously have. Neither 'fundamental' needs in Miller's sense nor 'absolute' needs in the sense discussed here are by definition either universal or immutable. Fundamental or absolute needs can be particular and mutable. Such needs are only universal (within a species) and immutable when specified at a high level of abstraction that can obscure morally and prudentially relevant differences, such as the differences in nutritional requirements between a pregnant woman and a middle-aged man with a heart condition.

As well as one's absolute biological needs, one has absolute agency needs. These include, but outstrip, one's absolute biological needs. Should one's agency needs continue to

\footnotetext{
${ }^{35}$ Miller, op. cit. note 21, p. 4. Since her list of 'The Fundamental Needs of Agents' (ibid: 41-42) includes some goods, such as nutrition, water and rest, with which some agents can provide themselves, the inclusion of 'that others must meet' rather than, for example 'must be met', seems to be a mistake.

${ }^{36}$ Ibid: 22 .
} 
go unmet, one's agency will dissipate or disappear. Survival needs are absolute existence needs. Welfare needs outstrip existence needs; perfectionist needs, in turn, outstrip welfare needs. Welfare needs as here conceived concern functional normalcy, whereas perfectionist needs concern functional excellence. Neither our conception of what it is for a human being to be functioning normally nor our conception of what it is to be an excellent human being are value-free. Our conceptions of health and of intellectual and moral virtue are normative in the sense that they embody evaluative standards. It is relative to these standards that we evaluate the welfare of individuals and by which we judge the quality of our practice in such fields as healthcare, education and child-rearing. When attributing needs to humans, the further away we get from survival needs the more likely it is that our attributions will not be independent of standards of evaluation. Among those needs that we have merely in respect of being biologically human, rather than in respect of being personal agents, survival needs are absolute and their recognition is independent of evaluative standards. This last point is developed in the next section.

\section{NEEDS AND VALUES}

We may distinguish between three ways in which (some or all) attributions of need have been characterized as 'normative' by authors of works about needs. First, they are sometimes taken to be expressively normative. An attribution of need is expressively normative when it expresses a command or a pro-attitude held by the speaker. ${ }^{37}$ Second, they are sometimes taken to be evaluative. An attribution of need is evaluative when it is true relative to a standard of goodness, such as is embodied in a conception of welfare, of health, or of

\footnotetext{
${ }^{37}$ For attributions of this view to other writers, and lists of references, see A.R. White. 1975. Modal Thinking. Oxford: Blackwell: 122 note 6; Thomson, op. cit. note 4, p. 136 note 8.
} 
flourishing. ${ }^{38}$ Third, they are sometimes regarded as having practical import in the sense that they are fit to serve as justifying reasons for actions. ${ }^{39}$ If an attribution of need is expressively normative or evaluative, then it expresses an attitude or belief about the good, or about what it is to be a good exemplar of a certain kind of thing. While attributions of need that are expressively normative or evaluative might have practical import, in that such attributions might describe justifying reasons for actions, the possession of practical import by a given attribution of need does not logically entail that that attribution of need is either expressively normative or evaluative.

Given the threefold distinction between existence needs, welfare needs and perfectionist needs, support for a real distinction between absolute needs and instrumental

${ }^{38}$ Wiggins, op. cit. note 6, p. 11 , characterizes claims of absolute need as normative because:

the suggested elucidation [of claims of absolute need] in terms of harm exposes a certain parameter that is always there to be discovered within claims of absolute needing. This is the idea [. . .] of well-being or flourishing, by reference to which we make judgements of harm.

Compare Thomson, op. cit. note 4, p. xii: 'the notion of a [. . ] non-instrumental need is a normative concept because it pertains to serious harm'; Miller, op. cit. note 21, pp. 17-18. Compare also P.M.S. Hacker. 2007. Human Nature: The Categorial Framework. Oxford: Blackwell: 133: 'What we deem absolute needs depends upon our conception of health, and hence upon our conception of the optimal functioning of a normal member of the species.' Note, though, that Hacker's conception of absolute need differs from that set out earlier in this article: he does not take absolute needs to be independent of all ends whatsoever, but to be 'ends [which are] independent of contingent goals' (ibid: 132).

${ }^{39}$ For related material, see E.J. Lowe. 2005. Needs, Facts, Goodness, and Truth. In The Philosophy of Need. S. Reader, ed. Cambridge: Cambridge University Press: 161-173. As part of an externalist account of practical reason, Lowe views needs themselves as justifying reasons for action. For the view that facts about need play this role, see M. Ramsay. 1992. Human Needs and the Market. Aldershot: Avebury: 2, 17-48. Thomson op. cit. note 4, e.g. pp. 4-9 associates the 'absolute' sense of 'need' with practical necessity. 
needs does not entail commitment to the view that all claims of biological need are essentially normative in any of these three senses. ${ }^{40}$ The case of survival needs shows that it not necessary for attributions of biological need to depend upon norms or values. This is so even if there are norms that depend upon survival needs: for example, if an agent's conscious ends are apt to be evaluated, prudentially or morally, in respect of their consistency or otherwise with the meeting of the agent's survival needs considered as an objective interest. Survival needs, and biological needs in general, might be held to serve as justifying reasons for action. Such a position, however, relies upon controversial views about practical reason: it is neither inevitable nor a logical requirement that someone who accepts that there are absolute biological needs should have to consider attributions of such needs to be essentially normative in any sense. Someone might, for example, admit that there are absolute biological needs while holding that only beliefs and desires can serve as justifying reasons for action. Biological need, since it is ontologically independent of personal agency, is ontologically independent of practical reason. Moreover, the earthly genesis of biological need predates that of practical reason. If there is any essential connection between biological needs and justifying reasons, it falls short of being an identity. Any essential dependency is of the reasons upon the needs.

Statements of survival need concern merely what it is to continue to be a living entity of a species (rather than to be a good or unharmed exemplar of the species). They are innocent of value-laden notions. Thus, the contentions that all claims of need (or, more minimally, all claims of absolute need) are normative, in the sense that they are (or are

\footnotetext{
${ }^{40}$ The phrase 'essentially normative' is used here so as to allow for cases, familiar in linguistics and the philosophy of language, in which a speaker utters a declarative sentence with a communicative intention other than the statement of a fact. It is intended to mark the distinction between types of declarative sentence that cannot but carry normative meaning and those which may occasionally do so, as a matter of pragmatics, but which need not do so.
} 
closely analogous to) imperatives stating what must be done, or that they are evaluative, in the sense that they depend upon notions such as those of harm, well-being and flourishing, can both be rejected. Moreover, if survival needs are normative in the sense that they are (or can be) justifying reasons for action, it is value that is dependent on need, not need that is dependent on value. The identification of an organism's survival needs is a matter for purely empirical inquiry.

\section{CONCLUSION}

There are absolute biological needs. These needs are prior to instrumental needs in the sense that an organism with instrumental needs cannot have those instrumental needs without having the biological needs, though it must have the biological needs whether or not it has instrumental needs. The defence of absolute need mounted here does not depend on any claims about the semantics of the verb 'need'. Moreover, it does not involve subscription to the view that claims of absolute need must be normative or evaluative in any sense which entails that they are value-laden claims, while leaving open the possibility that biological needs, or facts or beliefs about them, are normative in the sense of furnishing personal agents with justifying reasons for action.

\section{Acknowledgements}

I am grateful to members of an audience at Durham University, especially Jonathan Lowe and the late Soran Reader, to whose memory I dedicate the article, for discussion of some of this material. Thanks to two anonymous referees for their suggestions for improvement.

Stephen McLeod is a lecturer in the Department of Philosophy at the University of Liverpool. He is the author of Modality and Anti-Metaphysics (Aldershot: Ashgate, 2001) and 
has published journal articles on needs, existence, modality and the philosophy of logic. 